\title{
The Empirical Analysis of the Introduction of Project Management Theory to the Apparatus of Association Construction
}

\author{
Yao Yao \\ School of Environmental Engineering, Wuhan Textile University, Wuhan 430200, China \\ Email: yaoyao1145@sina.com
}

Keywords: project management theory, professional association, empirical analysis, educate students through practice

\begin{abstract}
Professional societies with professional characteristics of scientific research activities, the second classroom platform will be scientific research and student autonomy activities together to foster students a good sense of innovation and innovation, a new era of ideological and political education in the new position. This paper intends to start from the plight of restricting the development of college student associations, to study the function and mode of project management theory on the construction of professional associations, to explore how to enhance professional associations in terms of building a scientific management mode, thus establishing a community management mechanism and formulating a process management system Self-construction.
\end{abstract}

\section{Introduction}

Institution of higher education' $s$ scientific and technological plan for medium and long-term(2006-2020) has clearly put forward that the aim of higher education is to cultivate advanced talents with comprehensive qualities as well as innovative spirit and practice ability ${ }^{[1]}$. So cultivating innovative talents becomes essential meaning of higher education. Therefore, this paper use the project management theory to instruct the management and the organization of professional associations, explore the beneficial development methods of how to elevate professional associations and the mode of promoting talents cultivation so as to solve the difficulties in their self-construction effectively.

\section{The plight of college professional associations under the project management perspective}

\subsection{Incomplete management system lags the development of the associations}

To establish an effective management system is the foundation of the corporate sustainable development of all the associations, which most of them always lack. On one hand, most professional associations are led by the School League Committee and its management is attached to professional related department, forming double administration. On the other hand, students' associations lack a set of effective internal management system to evaluate the achievements of their activities and inspire their members' actions, which results in their members' exiting randomly at any period. Therefore, the project sustainability is poor and the flow of the members is frequent.

\subsection{The simplex construction funding source restricts the associations' development scale}

On one hand, the amount of subsidization fees is not high enough and is distributed according to the number of the associations, thus it can't be distributed according to associations' actual need and output. On the other hand, the fees charged from associations' members are just enough to maintain its work of the daily management. The lack of students association's ability to raise social funds has a direct effect on their number and the quality, leading to the poor quality of the association activities, the limit of members' participation and coverage, thus restrict their development and expansion. 


\subsection{The insufficient ratio of the professional guidance teachers weakens the professional degree of the associations}

The development of the professional associations depends on the professional background and knowledge accumulation, and it must correspond to the needs of times. Moreover, their development should be led to a characteristic and specialized road and carry out competitions and research activities combined with professional background. So it is very difficult to conduct comprehensive and professional instruction just depending on the full-time instructors of the School Youth League Committee or the departments, which also can provide them with limited technical support and professional guarantee.

\section{The feasibility and necessity analysis of introducing project management theory to the construction of professional associations}

\subsection{The connotation and tools of project management}

The three kinds of tools of project management can be used in the planning, implementation and controlling stage of the association activities. The first kind is the work breakdown structure table (WBS). Applying WBS in the planning stage of association activities can help make detailed schedule plan, resource needs, cost budget, etc in detail. The second one is linear responsibility table that is showing each member's duties and the authority-responsibility relationship between their cooperation with each other in a specific task during the period of the project management. The last one is Gantt diagram, which can vividly show the order of any certain activity and its duration through event list and schedule in the way of graphical representation ${ }^{[2]}$. It can help know the implementation of project activities in time and evaluate the progress of project to use this way in the association activities.

Table 1 WBS of a project operation (Water project of environmental funding)

\begin{tabular}{|c|c|c|c|}
\hline Level 1 & Level 2 & Level 3 & Level 4 \\
\hline \multirow{37}{*}{$\begin{array}{l}\text { Baihu wetland } \\
\text { line project }\end{array}$} & \multirow{7}{*}{ Start-up phase } & \multirow{3}{*}{ Collect message } & Environmental creative project notice \\
\hline & & & Foundation project bidding \\
\hline & & & Entrepreneurship creative competition notice \\
\hline & & \multirow{2}{*}{ Demand analysis } & Positioning itself \\
\hline & & & Determine the conditions \\
\hline & & Write planning & Content design \\
\hline & & Project report & Project declaration \\
\hline & \multirow{12}{*}{ Preparation stage } & \multirow{4}{*}{ Publicity preparation } & Propaganda program \\
\hline & & & Poster production \\
\hline & & & Public number promotion \\
\hline & & & Team uniform custom \\
\hline & & \multirow{4}{*}{ Material preparation } & Buy equipment \\
\hline & & & Survey \\
\hline & & & Material estimation \\
\hline & & & Buy reagents \\
\hline & & \multirow{4}{*}{ Team building } & Personnel selection \\
\hline & & & Team training \\
\hline & & & Safe education \\
\hline & & & Coordinate the person in charge \\
\hline & \multirow{10}{*}{ Implementation phase } & \multirow{6}{*}{ Research } & Water quality sampling \\
\hline & & & Send questionnaires \\
\hline & & & Ecological survey \\
\hline & & & Water quality testing \\
\hline & & & Data summary \\
\hline & & & Draw a pollution map \\
\hline & & \multirow{4}{*}{ Publicity and educatio } & Brochure production \\
\hline & & & Write lesson plans \\
\hline & & & Primary education \\
\hline & & & Community education \\
\hline & \multirow{4}{*}{ Progress Control } & \multirow{2}{*}{ Detail management } & Activity stage summary \\
\hline & & & Time node to grasp \\
\hline & & \multirow{2}{*}{ Progress feedback } & Report regularly \\
\hline & & & Amend the implementation plan \\
\hline & \multirow{4}{*}{ Summary stage } & \multirow{2}{*}{ Exchange seminars } & Hold college forum \\
\hline & & & Water quality research report \\
\hline & & \multirow{2}{*}{ Project summary } & Results report \\
\hline & & & Papers published \\
\hline
\end{tabular}


Table 2 linear list of responsibility of project

\begin{tabular}{|c|c|c|c|c|}
\hline \multicolumn{2}{|l|}{ WBS } & Instructor & Project manager & Executor \\
\hline \multirow{4}{*}{ Start-up phase } & Collect message & & & $\boldsymbol{\Delta}$ \\
\hline & Demand analysis & 0 & $\Delta$ & \\
\hline & Write planning & & $\Delta$ & \\
\hline & Project report & 0 & $\boldsymbol{\Delta}$ & \\
\hline \multirow{3}{*}{ Preparation stage } & Publicity preparation & & 0 & $\boldsymbol{\Delta}$ \\
\hline & Material preparation & & ○ & $\boldsymbol{\Delta}$ \\
\hline & Team building & & 0 & $\boldsymbol{\Delta}$ \\
\hline \multirow{2}{*}{ Implementation phase } & Research & & 0 & $\boldsymbol{\Delta}$ \\
\hline & Publicity and education & & 0 & $\boldsymbol{\Delta}$ \\
\hline \multirow{2}{*}{ Progress Control } & Detail management & & 0 & $\boldsymbol{\Delta}$ \\
\hline & Progress feedback & & O & $\Delta$ \\
\hline \multirow{2}{*}{ Summary stage } & Exchange seminars & - & $\Delta$ & \\
\hline & Project summary & O & $\Delta$ & \\
\hline
\end{tabular}

Oindicates approval, indicates auxiliary, $\boldsymbol{\Delta}$ indicates principal

Table 3 Gantt diagram of cycle brand activities of an association

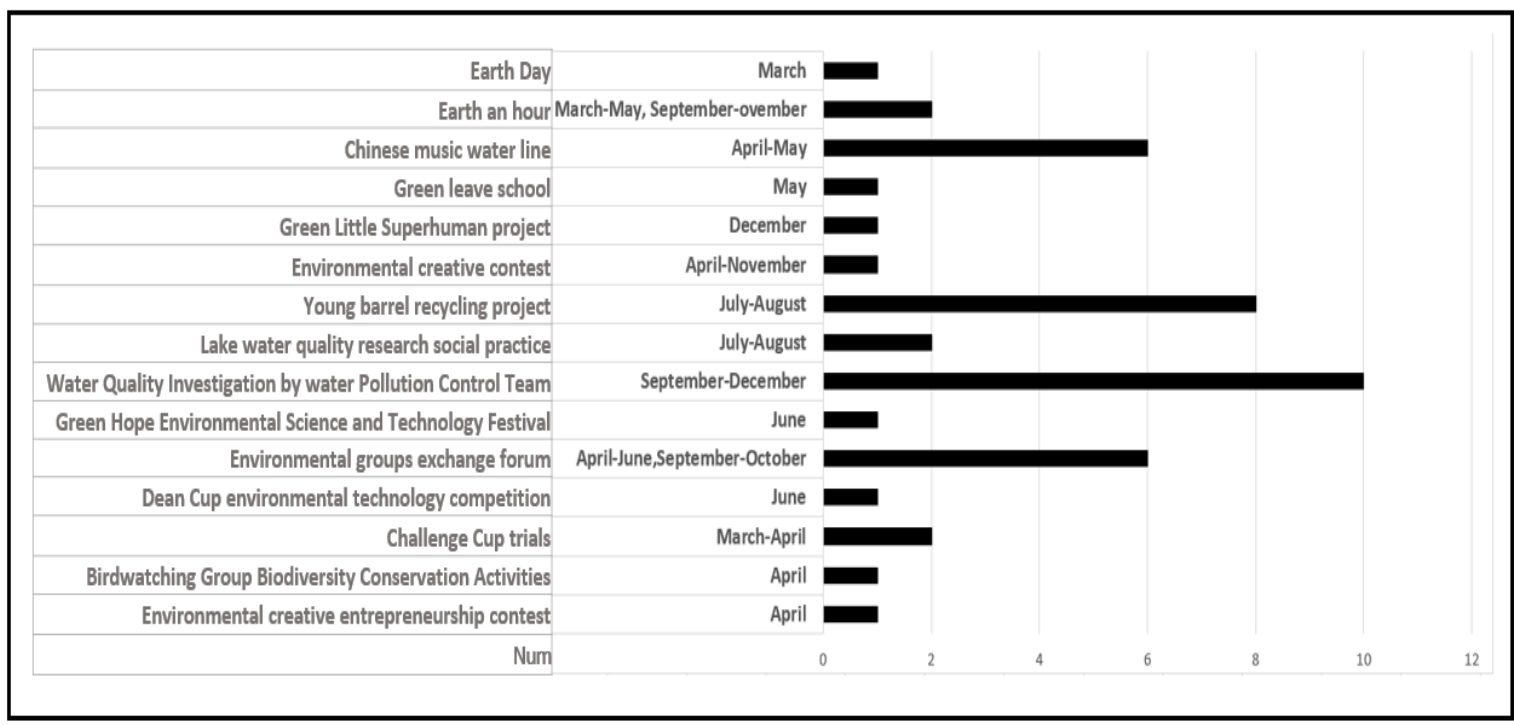

\subsection{The feasibility and necessity of applying the project management theory to the construction of professional associations}

Firstly, compared with social enterprises and public interest organizations, the scales and functions of professional college associations are much smaller, but they have similarities in organization structures and management system, such as there is a common goal as an organization and different institutions in internal organization. Therefore, it is viable to apply the methods of the project management widely used in the enterprises to the construction of college associations and their activities. Secondly, the management of college associations mainly relies on experience and traditional habits at present while they rarely apply project management theory in each activity of students associations, which causes the ways of construction and management concepts of students associations can't be joined with society effectively, and is not good for students to adjust themselves to the needs of work. So there is great researching space and practical value to bring project management theory into the construction of students associations for it can develop students' abilities of overall planning and management by objectives, and promote students' comprehensive qualities as well. 


\section{The application exploration of project management in the construction of professional associations}

\subsection{To revise rules and regulations around integrated management and to build scientific management mode}

Project integration management is a process that must be carried out to guarantee each component works properly and harmonically. It needs institutionalization to guarantee and restrain the members' behaviors so that the activities of professional associations can conduct management by project. After conducting management by objectives, target management can be achieved by enacting supplementary rules, such as project application rules, project periodic acceptance management system and bacteria for assessment of member performance targeted for "quantitive" indications, so that members of the association are clear of the standards by which they can achieve the objectives in work with more activity. Therefore, colleges and universities should explore and build the evaluation system and incentive mechanism which are in favor of the management by project as soon as possible, and not only set up the guidance but also make profit ${ }^{[3]}$.

\subsection{To confirm the development mechanism around management by objectives and promote continuous innovation ability}

Management by objectives was first put forward by Peter F. Drucker, a management expert. ${ }^{[4]}$ He think that bringing management by objectives into professional associations can bring about two practical effects: first, it is beneficial to determining the development direction and mode of the association, for the goal has been determined at the beginning of the start of the activity, and it has also been confirmed from the association's top members to its ordinary members after they made the medium and long-term goals and plans based on strengthening communication within the team and reaching an agreement. Second, it is to the benefit of strengthening the sustainable development power of the association. As the degree of team members' participation affects the output of the project results, so it can ensure that the goal will be completed smoothly through arousing the enthusiasm of team members, motivate their innovation thinking mode and ways to work, and perform the goal from bottom to top.

\subsection{To set up activities standardized system by start using process management and increase the bid acceptance probability of the project fund}

Process management is also called PDCA circulation, including planning, implementation, monitoring and improvement, which can optimize the project implementation process, change the function of the manager's job and improve the effect of project management. Studies have pointed out that a structured activity is better than an unstructured activity in the results of promoting enthusiasm ${ }^{[5]}$. First, Starting using process management in the professional associations can transform the administrators of universities and departments from directly involving and instructing the activities in the past to the bidding, evaluation and supervision of the activities as well as the construction of the project management system. Second, Starting using process management in the association's specific projects is able to strengthen cooperation between student, communication between students and teachers, and improve students' executive ability, which can help trace the responsibility, control the process and improve the operation efficiency of the activities.

\subsection{To set up standardized operation team relying on human resource management and strengthen instructors' engagement}

The introduction of human resources management to promoting self-operation of the professional associations includes three dimensions: the first one is the dimension of the professional instructor' engagement. The activities organized in the form of "project team" set every activity as a fixed team, which changes the previous cycled and rigid management of all activities that depend on individual decision makers, thus it gives full play to professional instructors involved in the project activities and promote their engagement. The second one is the 
dimension of the improvement of the ability of project team members. Activity project can promote the refining of the members' labor division and motivate students' interests to take part in the activities. The diversity of the project tasks requires team members to have the advantages of diversity, promoting their ability of dealing with and solving the problems and their comprehensive abilities. The third one is the dimension of benignant development of the association.

\section{The empirical application of the construction project management of the professional associations taking the national top hundred associations for example}

The Green Environmental Protection Association of Wuhan Textile University take the exerting the advantages of environmental engineering major, propagandizing environmental protection concept, participating academic researches and conducting practice activities of investigate and survey a s its main contents. It is a college students association with profession, commonweal and academic as a whole, which owns 1,500 registered members. The association pays much attention to the integration of the professional disciplines background and the brand advantages of the national top hundred associations in its running process, to the introduction of project management theory and self-organization theory to explore the education mode of the professional associations.

\subsection{Combined with talents training characteristics, to locate the development direction around the development goal of the association}

First of all, set target locations for different periods. The association has changed for three times: from campus to society, from activities to social practice and from environmental propaganda and education to environmental protection research, then finally positioned itself as a professional association with commonweal features. Second, the association attaches great importance to building voluntary services, professional practice and scientific research of environmental commonweal to practice the three systems around the goal of cultivating entrepreneurial young talents with the spirits of environmental commonweal. Third, scientific research incubation boosts the conduction of the work of creativity and entrepreneurship, and forms an effective link of college students' commonweal enthusiasm and commonweal practice.

\subsection{To set up standard operation system and achieve self-hemopoiesis on the basis of brand project application}

The association brought in project process management to build project application standard operation. On one hand, to dig out the characteristics of itself and to form project classification application according to different activity contents and to widely apply for the public bidding social practice projects offered by public welfare foundations, government agencies and enterprises, which have sufficient funding guarantee. To operate in the way of the processes of application---project approval---interim report---post-project acceptance is very beneficial to build a team managed by project. Up to now, the association has set ten annual cycle projects and three competition cycle projects, undertaken the environmental education project the Little Green Superman of Pizza Hut for five years in a row and two national green off schools activities, studied and applied three projects of province education department's subject and practice education projects by using the development mechanism and education mode of the Green Environmental Protection Association. On the other hand, to provide the designs of customized commonweal environmental protection activities according to the necessity of the responsibilities of enterprises and society in order to gain corresponding funding support, achieve the mutual benefit of both sides. To some degree, it alleviates the shortage of funds to some degree for it gets more than 20,000 yuan annually declare the projects when the organization members can improve their ability through taking part in activities and have self-hematopoies is at the same time.

\subsection{To strengthen the advisors' degree of participation and promote the professionalization of the activities on the basis of the construction of scientific research team}

First, the association takes "the double tutorial system", building the double tutorial mode of 
which the instructors of the professional association are in charge of the planning and the schedule management of the association's whole activity and the professional teachers participate in the scientific research instruction activities. Second, setting up the project team of professional direction and establishing project team competition system, the association formed four project teams: water quality monitoring of Hubei typical lakes, water pollution control technology and application, innocent treatment of lake's heavy metals and the study of ramie cleaner production technology. Through decision-orientated study, they published more than 20 core journal articles and more than 30 approved patents. Their results of sewage treatment research won two second prizes of the National Challenge Cup and 10 awards of Hubei Province Challenge Cup, the water pollution governance team was evaluated as the 2015 annually national college students Xiao Ping science and technology innovation team. The professional cultural background of the association has continuously strengthened.

\section{Conclusion}

To explore the mode and beneficial approach of talent cultivation under the background of the new times is actually to have methods and carriers innovated and the problem of how to cultivate the fresh troops of innovative talents with rich professional background knowledge combining with the characteristics of students in new times and social theme. This research enhances its institution improvement and scientific management, although the association has achieved certain effect in applying project management to the construction of the professional association, which is a beneficial exploration to bring in project management to the construction of the professional association

\section{Acknowledgements}

This paper is a periodic achievement of an ideology and politics special research project of Hubei provincial educational department entitled "exploration on higher education synergy system in practice based on environmental clubs” (project No:1617YA02) as well as Hubei Province college student work boutique project "professional community services to explore the growth mechanism of university students" (project No: 2017XGJPF3018)

\section{References}

[1] People's Republic of China Ministry of Education. College long-term science and technology development planning (2006 - 2020). [M]. Tsinghua University Press .2014

[2] AnbangQi. Project Management. [M]. Nankai University Press .2014

[3] Lihua Zhou. On the Innovation of Project Management in Student Organizations in Colleges and Universities. China Adult Education .2009 (24), P53- P54

[4] Goal Management. Http://wiki.mbalib.com/wiki/ Goal Management. December 26, 2016.

[5]Joseph Muffy, Danny Ira Thor, Campus Culture: Discovering the Value of Communities. [M]. Heilongjiang Education Press .2016, P67 